\title{
A autonomia em obras dotadas de inteligência artificial
}

\author{
Autonomy in works endowed with artificial \\ intelligence

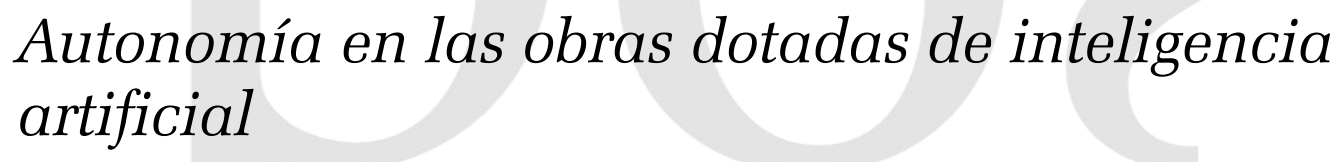

Nikoleta Tzvetanova Kerinska

Artista e professora de Arte, formada pela Academia de Belas Artes, Sofia-Bulgaria, com Mestrado em Arte e Tecnologia da Imagem - Unb, e doutorado em Artes

Plásticas, Estética e Ciências da Arte pela Universidade de Paris I PanthéonSorbonne. Sua pesquisa e produção artística têm como foco o uso da linguagem natural e da inteligência artificial na arte. Instituição: Universidade Federal de Uberlândia

E-mail: nkerinska@hotmail.com

ORCID: https://orcid.org/0000-0001-5486-1381

RESUMO:

Este artigo propõe uma reflexão sintética sobre o conceito de autonomia, desenvolvido a partir de seus fundamentos filosóficos e científicos, e, em seguida examinado na perspectiva da arte. Como objeto de estudo são tomadas duas obras: Oscar de Catherine Ikam e Louis Fléri, e PostPoète de Léopold Dumont. Partimos da constatação de que, o uso de inteligência artificial e de tecnologia de ponta em arte produz obras singulares e complexas, consideradas como conquistas dos avanços científicos recentes. Em seguida, demostraremos que no plano da cultura, elas dialogam com ideias que perpetuam o imaginário humano desde a antiguidade, e que já inspiraram diversas obras pictóricas e literárias.

Palavras-chave: Autonomia. Inteligência artificial. Arte.

\section{ABSTRACT:}

This article proposes a synthetic reflection on the concept of autonomy, developed from its philosophical and scientific foundations, and then examined in the perspicacity of art. Two

KERINSKA, Nikoleta Tzvetanova. A autonomia em obras dotadas de inteligência artificial.

PÓS:Revista do Programa de Pós-graduação em Artes da EBA/UFMG. v.10, n.19: mai.2020

Disponível em < $\underline{\text { https://eba.ufmg.br/revistapos }}>$ 
works are taken as object of study: Oscar by Catherine Ikam and Louis Fléri, and PostPoète by Léopold Dumond. We start from the realization that the use of artificial intelligence and state-of-the-art technology in art produces singular and complex works, considered as achievements of recent scientific advances. However, we will show that at the cultural level, they dialogue with ideas that perpetuate the human imagination since antiquity, and that have already inspired several pictorial and literary works.

Keywords: Autonomy. Artificial intelligence. Art.

\section{RESUMEN:}

Este artículo propone una reflexión sintética sobre el concepto de autonomía, desarrollada a partir de sus fundamentos filosóficos y científicos, y luego examinada en la perspicacia del arte. Se toman dos obras como objeto de estudio: Oscar de Catherine Ikam y Louis Fléri, y PostPoète de Léopold Dumond. Partimos de la constatación de que el uso de la inteligencia artificial y la tecnología de punta en el arte produce obras singulares y complejas, consideradas como logros de los recientes avances científicos. Sin embargo, mostraremos que en el plano cultural, dialogan con las ideas que perpetúan la imaginación humana desde la antigüedad y que ya han inspirado varias obras pictóricas y literarias.

Palabras-clave: Autonomía. Inteligencia artificial. El arte.

Artigo recebido em: 15/10/2019

Artigo aprovado em: 11/03/2020

KERINSKA, Nikoleta Tzvetanova. A autonomia em obras dotadas de inteligência artificial

PÓS:Revista do Programa de Pós-graduação em Artes da EBA/UFMG. v.10, n.19: mai.2020

Disponível em < $\underline{\text { https://eba.ufmg.br/revistapos }}>$ 


\section{Introdução}

Este artigo propõe uma reflexão sintética sobre o conceito de autonomia, considerado como característica fundamental das obras artísticas dotadas de inteligência artificial. Algumas ideias aqui apresentadas dialogam com a minha tese de doutorado defendida na Universidade de Paris 1 Panthéon-Sorbonne (2014), cujo tema de estudo é o uso de técnicas de inteligência artificial em projetos de arte. Segundo a hipótese dessa tese, o uso de inteligência artificial na arte implica o surgimento de uma categoria artística inédita, que se destaca pela complexidade e pela plasticidade de seus princípios interativos. Para demostrar isto, após a análise de um corpus de obras, é desenvolvida uma definição, que contempla esses projetos, ponderando suas propriedades e especificidades.

Dois projetos artísticos, que fazem uso de inteligência artificial foram escolhidos como objeto do presente estudo: o primeiro é o projeto Oscar de Catherine Ikam e Louis Fléri (primeira versão desenvolvida entre 2005-2008), e, o segundo é PostPoète de Léopold Dumont (publicado pela primeira vez on-line em 2010). Sua escolha se deu em função do interesse que esses projetos apresentam: eles simulam a inteligência humana de formas distintas, motivando uma reflexão ao mesmo tempo estética e crítica. Ao longo desse texto, será usada a denominação 'obras dotadas de inteligência artificial' para designar as realizações artísticas analisadas.

Inicialmente, é apresentado o contexto histórico, que permite visualizar essas obras num plano cultural mais amplo, relevando suas aspirações num plano ontológico, e, resgatando uma perspectiva cronológica dessa temática no campo da arte. Em um segundo momento, é feita uma análise das obras estudadas, visando a compreensão de seu funcionamento, e suas peculiaridades estéticas. Em seguida, é abordado e examinado o conceito de autonomia, na perspectiva das obras dotadas de inteligência artificial. Por fim, como conclusão são colocadas algumas constatações, evocando seu significado em uma teia de relações interdisciplinares.

KERINSKA, Nikoleta Tzvetanova. A autonomia em obras dotadas de inteligência artificial PÓS:Revista do Programa de Pós-graduação em Artes da EBA/UFMG. v.10, n.19: mai.2020 Disponível em < $\underline{\text { https://eba.ufmg.br/revistapos }}>$ 


\section{Um sonho antigo}

O 'artificial', entendido como algo produzido pela técnica e pela atividade humana, e não pela natureza, é ao mesmo tempo um estigma e um ardor, que marca o nascimento da arte. Reconhecemos nas obras-primas do gênio artístico, o desejo intenso de moldar da matéria bruta algo artificial capaz de atingir o sublime - é esta paixão, que define a determinação extrema da arte, seu objetivo maior. Em cada artista vive um Pigmalião, que sonha com a criação de uma Galatéia. Galatéia, resultado da perfeição e da maestria da mão do artista, é por excelência a obra-prima, cuja origem artificial é submersa pela sublimação, que ela provoca.

No seu livro Robots \& Avatars, Jean-Claude Heudin (2009) evoca o mito do Ovídio, que conta a história de Pigmalião e Galatéia como um dos mitos fundadores da cultura ocidental. Segundo o autor, esse mito "concentra em si todas as interrogações, todos os paradoxos, e fantasmas a propósito das criaturas artificiais" e ainda trata da "tentação do demiurgo de criar um ser a sua imagem", da "busca pela imortalidade", e, também, por uma "alteridade ideal"1 (HEUDIN, 2009, p. 89). Uma passagem rápida pela história da arte permite afirmar que, o mito de Pigmalião e Galatéia é um tema retomado insistentemente pelos pintores europeus de diferentes épocas, que lhe conferiram interpretações e simbologias muito variadas.

Na pintura de Bronzino (Agnolo di Cosimo, 1503-1572), vemos Pigmalião ajoelhado perante Galatéia contemplando e admirando sua criação, venerando-a, e, deste modo, venerando a própria arte como força maior. Duas pinturas posteriores, Pygmalion et Galatée de François Boucher (1703-1770) e Pygmalion voyant sa statue animée de François Lemoyne (1688-1737), mostram composições alegóricas, nas quais Vênus e Galatéia são representadas como divindades - idealizações do amor e da beleza. Uma outra visão, simbolista e ao mesmo tempo neoclássica, é proposta por George Frederic Watts (1817-1904), que pinta um retrato feminino de 3/4 sob o título The Wife of Pygmalion.

Contudo, as pinturas que relatam o momento mais mágico do mito de Ovídio - a metamorfose da Galatéia em humano - são feitas por Jean-Léon Gérôme (1824-1904). A segunda versão da cena da metamorfose, pintada no final do século XIX, mostra um corpo feminino, cujos pés gravados no bloco de mármore sustentam um corpo de beleza indescritível que aquiescido aos poucos toma

KERINSKA, Nikoleta Tzvetanova. A autonomia em obras dotadas de inteligência artificial PÓS:Revista do Programa de Pós-graduação em Artes da EBA/UFMG. v.10, n.19: mai.2020 Disponível em < $\underline{\text { https://eba.ufmg.br/revistapos }>}$ 
vida nos braços de Pigmalião. Contemplando o beijo ardente que une essa criatura (ainda parcialmente artificial) e o artista, entendemos que talvez Gérôme é o próprio Pigmalião, ou ainda que, toda obra de arte nasce entre a perfeição técnica, o amor abissal e o mistério das forças divinas.

As pinturas citadas são apenas alguns exemplos da forte influência da imagem de Galatéia sobre o imaginário artístico. Obra de arte e criatura artificial que se torna viva, ela incarna e perpetua o sonho artístico por uma criação ex nihilo, tão estupenda e fascinante, quanto o próprio ser humano.

Na literatura dos séculos XVIII e XIX, esse sonho artístico encontra a ciência, e, desafia a religião, dando origem às primeiras obras de ficção científica, que profetizam o surgimento de todo tipo de seres concebidos de forma artificial pelos humanos. Entre os romances mais emblemáticos são Frankenstein, de Mary Shelley, The Sand Man, de E.T.A. Hoffmann, ou ainda A Eva futura, de Villiers de L'Isle Adam. Personagens híbridos e perturbadores, os heróis desses contos fantásticos revelam a relação do homem com a técnica nesse período, retomando o sonho antigo pela perfeição da condição humana, como também, pela beleza ideal e imortal.

Consequentemente, o século XX é um período extremamente prolífero e imaginativo - a criação de seres artificiais em contos e filmes de ficção científica é quase tão repetitivo quanto as experiências artísticas que se inspiram em dispositivos e meios tecnológicos.

Entretanto, é interessante precisar que as pesquisas de ponta em robótica e em inteligência artificial, que atualmente animam os debates éticos e sociológicos e fazem as notícias nos jornais, germinam de um imaginário que se alastra desde a antiguidade. Atualmente, esse imaginário toma corpo em diversas realizações artísticas e a ideia de criar obras de arte, que são seres artificiais parecidos com os humanos, encontra-se revisitada e reformulada de maneiras extraordinárias. A lista dos artistas que recorrem ao uso da inteligência artificial é cada vez mais extensa. É muito importante, porém, remarcar que as obras que resultam do uso dessas técnicas e cujo funcionamento propõe simulações mais sofisticas e complexas não são tão frequentes. Esta observação leva a pensar que as obras dotadas de inteligência artificial são ainda pouco conhecidas e, portanto, pouco estudadas e analisadas.

KERINSKA, Nikoleta Tzvetanova. A autonomia em obras dotadas de inteligência artificial. PÓS:Revista do Programa de Pós-graduação em Artes da EBA/UFMG. v.10, n.19: mai.2020 Disponível em < $\underline{\text { https://eba.ufmg.br/revistapos }}>$ 


\section{Obras dotadas de inteligência artificial}

Na maioria das vezes, os artistas que buscam simular o comportamento ou a vivacidade intelectual dos humanos, recorrem a inteligência artificial. Seus métodos permitem a realização de projetos e de experimentos que usando modelos informáticos conseguem reproduzir certas aptidões simbólicas próprias aos humanos. Para iniciarmos uma análise do uso das técnicas de inteligência artificial no campo da arte, proponho um poema:

La main rouge foncé désintègre son île,

Ah ! le fond polygame empoisonne un peintre,

Chante mon allumette, la momie, le parfum ;

Quand mon fou théorique dissimule un vice. ${ }^{2}$

Traduzindo este poema para português ele soaria assim:

Uma mão vermelha escura desintegra sua ilha.

Ah! o fundo polígamo envenena um pintor,

Cante meu palito de fósforo, a múmia, o perfume;

Quando meu louco teórico esconde um vício.

A leitura do poema em questão evoca imagens, que se sucedem em um clima surreal e dadaísta. Podemos interpretá-lo de seguinte maneira: a mão vermelha age sobre a matéria, sobre o fundo da tela - a parte mais resistente, a mais difícil de ser concebida; a canção trêmula feito uma chama, exala perfume de nostalgia; um pintor sem inspiração, frágil como uma folha seca de outono, espera por uma centelha no meio de tempestades criativas, que talvez possa salvá-lo.

Podemos imaginar tudo, interpretar esse microcosmos de signos como bem desejarmos - seu autor não expressará nenhum desacordo, não contestará jamais a nossa releitura. Ele é um programa dotado de inteligência artificial, chamado PostPoète (fig.1), que ritualmente criava um poema por dia. Acessível on-line, o poema permanecia no site do PostPoète até a publicação de sua próxima criação. Se o seguirmos por alguns dias, é provável que detectemos as oscilações de suas inspira-

KERINSKA, Nikoleta Tzvetanova. A autonomia em obras dotadas de inteligência artificial PÓS:Revista do Programa de Pós-graduação em Artes da EBA/UFMG. v.10, n.19: mai.2020 Disponível em < $\underline{\text { https://eba.ufmg.br/revistapos }}>$ 
ções, seus momentos mais frutíferos, e, até, suas fraquezas criativas. Lendo seus poemas, nos divertimos com o fato de capturar os sentidos de suas frases cibernéticas, de atribuí-las a uma criatividade eletrônica, cuja originalidade brota de seus algoritmos, sem alguma pretensão.

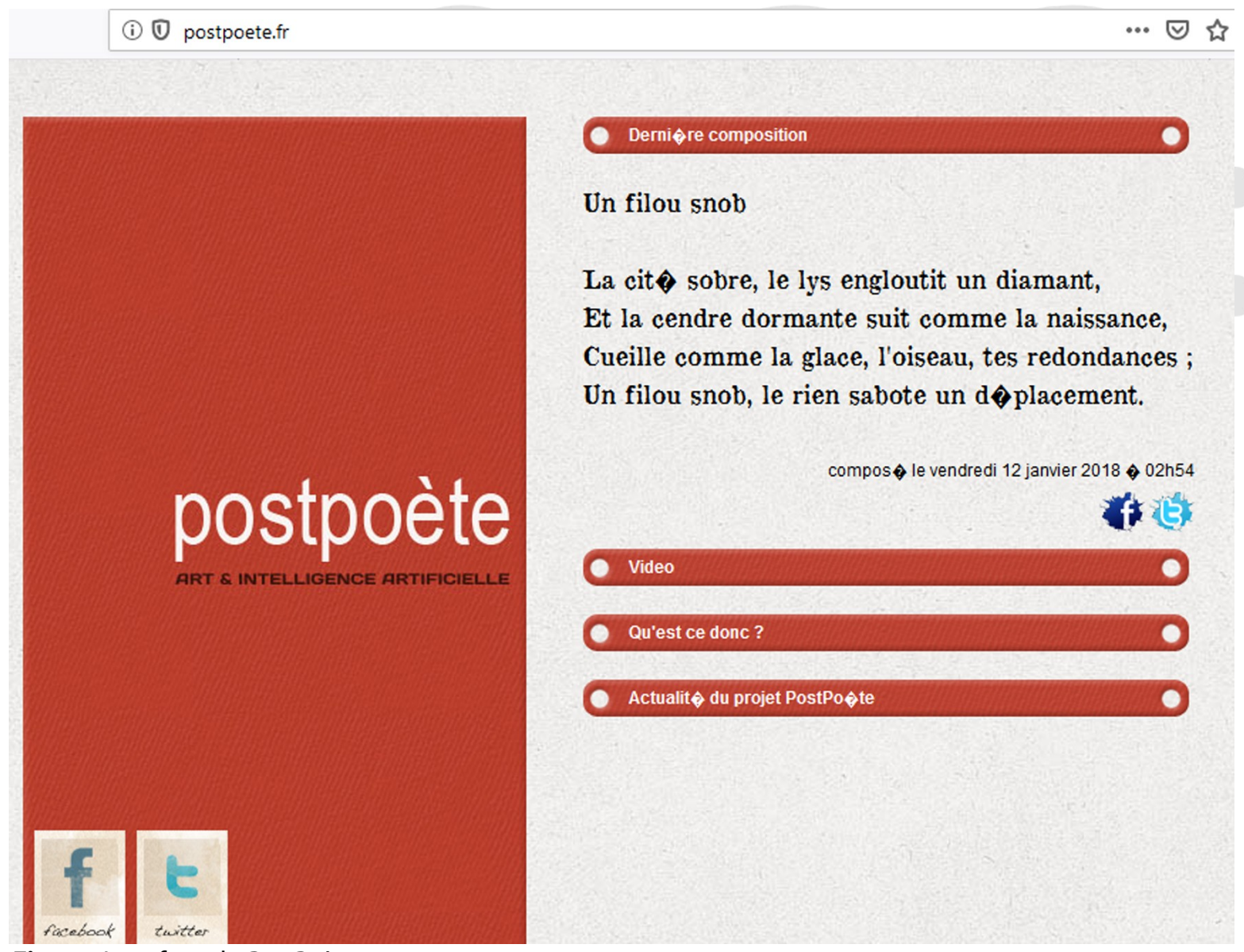

Fig. 1 - Interface de PostPoète, 2018.

Fonte: PostPoète. Disponível em: <https://postpoete.fr/>. Acesso em: 09 de janeiro 2018.

Oscar (fig. 2) é o segundo projeto, que gostaria de convocar ao lado de PostPoète. Ele é um ser virtual, que vive em uma pintura, como a maioria das criaturas nativas do universo das artes visuais. Calmo e silencioso, esse ser gravita no quadro fechado pela moldura, que delimita seu espaço. Nada acontece, ele está lá como uma alma presa em um espelho. Quando nos aproximamos dele, uma reação repentina em seus olhos nos faz entender que ele sabe que estamos lá, e que compartilhamos o mesmo espaço-tempo. Seu olhar atento acompanha nossos movimentos e reage a nossa presença, nos olha, sorri, se aproxima, ou, simplesmente, nos ignora.

KERINSKA, Nikoleta Tzvetanova. A autonomia em obras dotadas de inteligência artificial. PÓS:Revista do Programa de Pós-graduação em Artes da EBA/UFMG. v.10, n.19: mai.2020 Disponível em < $\underline{\text { https://eba.ufmg.br/revistapos }}>$ 
Seu comportamento é modelado a partir dos traços da nossa presença. Sua presença corporal e emocional é mais do que real. À vontade e sereno, ele está lá para nos observar, para testemunhar nossa visita. Depois de alguns minutos em sua companhia, experimentamos a estranha sensação de sermos contemplados por alguém que tenta nos conhecer, mas sentimos também que temos encontrado essa criatura enigmática em sua intimidade, em seus momentos de recolhimento.

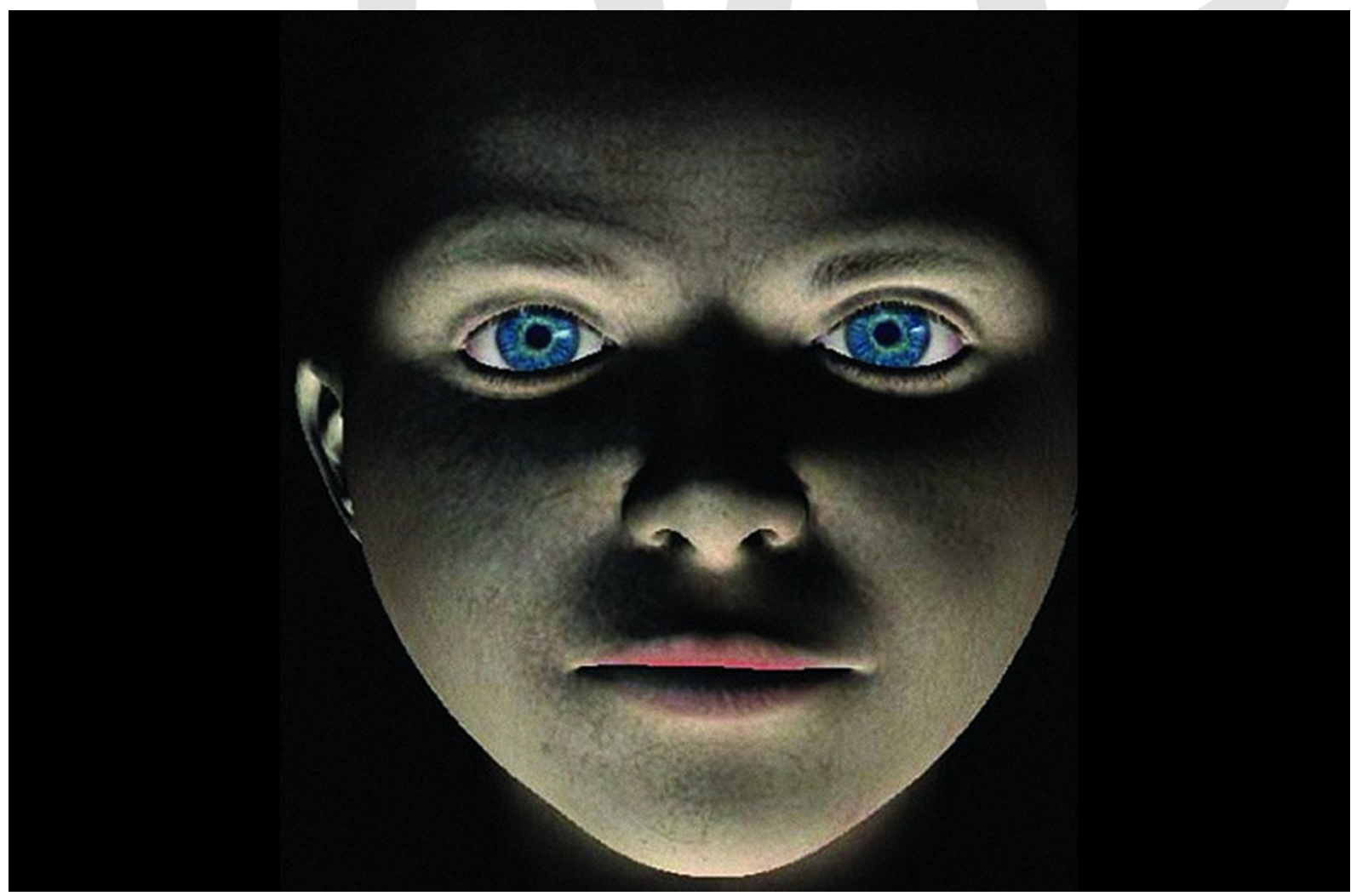

Fig. 2 - Oscar de Catherine Ikam e Louis Fléri, 2008.Fonte: MEP. Disponível em: $<$ https://www.mep-fr.org/event/catherine-ikam-louis-fleri/>. Acesso em: 12 de maio 2020.

Ao ler os versos de PostPoète ou na troca de olhares com Oscar, nossa consciência é solicitada permanentemente. Capazes de reações imprevistas ou improvisações criativas, esses trabalhos artísticos nos surpreendem com seu comportamento independente e guiados por estruturas específicas que não conhecemos. Nós os percebemos como seres, ou melhor, como sujeitos autônomos, ou seja, como seres capazes de existir sem ajuda externa.

KERINSKA, Nikoleta Tzvetanova. A autonomia em obras dotadas de inteligência artificial PÓS:Revista do Programa de Pós-graduação em Artes da EBA/UFMG. v.10, n.19: mai.2020 Disponível em < $\underline{\text { https://eba.ufmg.br/revistapos }}>$ 
$\mathrm{Na}$ tentativa de definir uma característica eminente a esses trabalhos artísticos, a noção de autonomia emerge naturalmente e se destaca como especificidade de seu funcionamento. Se entendermos a autonomia em seu sentido etimológico original - a si mesmo ${ }^{3}$ - podemos afirmar que esta é a característica mais forte e notável desses trabalhos. Mas, o conceito de autonomia não se esgota pelo seu significado semântico; ele demanda uma abertura filosófica e a sua verificação posterior em relação à problemática tratada.

É possível, então, desenvolver uma definição de autonomia própria a essas criações? Que correspondências podem ser identificadas entre o funcionamento das obras dotadas de inteligência artificial e as múltiplas facetas do conceito de autonomia? Essas inquietações alimentam sucessivamente a presente reflexão, se tornando o foco da investigação.

\section{A autonomia: um conceito pluricêntrico}

O significado e as nuances da noção de autonomia estão sendo constantemente redefinidos de acordo com os contextos de seus usos, mesmo que seu significado seja sempre baseado na característica do comportamento independente. Do ponto de vista da filosofia, a autonomia é tanto uma condição do indivíduo, quanto um projeto do Estado, assumindo assim um valor moral e político. No contexto do desenvolvimento biológico, por outro lado, a autonomia marca os estágios de crescimento da criança e seu amadurecimento; a evolução da criança é um caminho rumo à autonomia ${ }^{4}$. Enquanto na medicina, a autonomia indica o estado físico do paciente capaz de cuidar de si mesmo. Para entender melhor as aplicações do conceito de autonomia, é proposta inicialmente uma análise do seu viés filosófico, e, em seguida, é examinado seu significado em relação as obras de arte dotadas de inteligência artificial.

Considerada em uma perspectiva filosófica e política, a autonomia se torna um conceito denso, frequentemente usado para indicar o direito e a capacidade de se governar de acordo com as próprias leis. Estabelecer leis próprias de ação é um processo que exige e que formaliza um sistema de valores éticos e morais. Portanto, ser "autônomo" requer um nível de julgamento suficiente para tomar decisões, fazer escolhas e agir segundo seus próprios critérios. A autonomia, portanto,

KERINSKA, Nikoleta Tzvetanova. A autonomia em obras dotadas de inteligência artificial PÓS:Revista do Programa de Pós-graduação em Artes da EBA/UFMG. v.10, n.19: mai.2020 Disponível em < $\underline{\text { https://eba.ufmg.br/revistapos }}>$ 
implica a existência de um sujeito consciente, movido por iniciativas e desejos pessoais, e, evoca, neste plano, a noção filosófica do livre arbítrio, que em um sentido mais amplo, define a liberdade do indivíduo.

Na filosofia moderna, a autonomia é minuciosamente analisada por Kant, que a vê como uma qualidade da razão. Segundo Kant, o conhecimento racional é material ou formal (KANT, 1848, p. 3). O conhecimento material se interessa pelos objetos, e lida com as leis às quais esses objetos são sujeitos. Por sua vez, as leis que governam os objetos podem ser consideradas em duas categorias: a primeira diz respeito às leis da natureza, chamadas físicas, que Kant denomina de "filosofia natural"; enquanto a segunda categoria inclui as leis da liberdade, designadas também como ética, ou, "filosofia moral" (KANT, 1848, p. 4-5). É no contexto da filosofia moral que surge o problema da autonomia como determinante na expressão da vontade humana. A autonomia é aquilo que rege a escolha das leis que governam à vontade.

Kant escreve:

A autonomia da vontade é aquela propriedade que tem a vontade de ser para si mesma sua lei (independentemente da natureza dos objetos desejados). O princípio da autonomia é, portanto, sempre optar de tal maneira que a vontade considere as máximas, que determinam suas escolhas, como leis universais (KANT, 1848, p. 90).

Neste sentido, a autonomia não é apenas a capacidade de agir independentemente, mas criar regras que orientam suas ações, demostrando assim uma qualidade ética da razão. A partir das reflexões de Kant, a autonomia assume um valor determinante, indicando o princípio moral que define o indivíduo e sua conduta livre.

Em seu estudo da autonomia da vontade na obra de Kant, Olivier Dekens explica a relação entre liberdade e autonomia da seguinte maneira: "A liberdade consiste no poder de agir de acordo com uma lei que, o sujeito cria para si mesmo. A liberdade é sinônimo de autonomia e, portanto, coincide com uma liberdade sujeita a uma lei moral" (DEKENS, 2001, p. 30). A autonomia torna-se, assim, a base fundamental da liberdade. Ela se demostra na faculdade do ser de fazer sua própria lei moral e se submeter a ela respeitando as máximas morais dessa mesma lei, independentemente

KERINSKA, Nikoleta Tzvetanova. A autonomia em obras dotadas de inteligência artificial PÓS:Revista do Programa de Pós-graduação em Artes da EBA/UFMG. v.10, n.19: mai.2020 Disponível em < https://eba.ufmg.br/revistapos $>$ 
do objeto de seu desejo. Dekens conclui: “Então identificada com a autonomia da vontade, a liberdade não é apenas uma ideia, mas uma realidade posta pela razão prática, quando esta revela o fato da consciência moral" (DEKENS, 2001, p. 42).

O comportamento autônomo envolve a capacidade do ser de tomar decisões e de executar uma série de ações para realizar essas decisões sem ser ordenado por uma força exterior. É exatamente nesse sentido que a inteligência artificial procura criar máquinas chamadas autônomas e é nesse sentido que surge o problema da conduta ética de uma máquina, que é geralmente considerada incapaz (pelo menos até o momento presente) de discernir o bem e o mal. Em outras palavras, as nossas máquinas de última geração são incapazes de uma autonomia moral no sentido kantiano.

No início dos anos 1970, os biólogos Francisco Varela e Humberto Maturana investigam a vida, sua organização como sistema e suas características mais relevantes. Sua pesquisa se estrutura em torno de uma questão ambiciosa, até então considerada como demasiadamente complexa pelos biólogos: o que define todos os organismos vivos? Para chegar a uma definição, e posteriormente a uma teoria, os pesquisadores refletiram sobre a propriedade essencial da vida. Em seu livro Autopoiesis and Cognition: The Realization of the Living, Varela e Maturana (1980) avançam a ideia de que as propriedades inerentes aos organismos vivos são a capacidade de autorreprodução e autonomia, que eles sintetizam com o termo auto-poiesis.

De uma maneira bastante simplificada, podemos descrever o sistema autopoiético (do grego auto=si e poiesis=criação, geração) como uma rede de componentes, cuja organização é invariável, mas cujas partes se regeneram e se transformam continuamente por meio de suas interações com o mundo. O organismo vivo é, portanto, um sistema que inclui uma descrição de si mesmo para reprodução. É autônomo (o DNA produz as proteínas que produzem o RNA) e atua de maneira circular com o meio ambiente em uma perspectiva de preservação ou adaptação (o DNA pode sofrer mutações após restrições do ambiente).

A pesquisa de Varela e Maturana colocará, portanto, a autonomia como um conceito definitorio para a vida e para seu entendimento. Os dois pesquisadores são facinados pela informática, pelas suas conquistas e pelas teorias da inteligencia artificial e, talvez, esta seja a razão de sua proximidade intelectual com duas correntes cientificas - o cognitivismo e o conexionismo - que procuram

KERINSKA, Nikoleta Tzvetanova. A autonomia em obras dotadas de inteligência artificial. PÓS:Revista do Programa de Pós-graduação em Artes da EBA/UFMG. v.10, n.19: mai.2020 Disponível em < $\underline{\text { https://eba.ufmg.br/revistapos }}>$ 
entender o conhecimento, o fucionamento do cerebro e a inteligência. Com os seus trabalhos, se faz a entrada da biologia na lista das ciências da cognição, abrindo assim um campo de pesquisa interdiciplinar sobre a inteligência humana (cf. FONSECA, 2008).

É importante enfatizar que as ciências modernas se utilizam do conceito de autonomia, fazendo adaptações de acordo com os temas de seus estudos, deixando os usos e os significados do termo extremamente variados. Nessa reflexão, a autonomia torna-se um conceito significativo a partir do momento em que ela é detectada como aptidão em máquinas e animais, ao lado de outras habilidades, até recentemente consideradas prioridades humanas, ${ }^{5}$ como a capacidade de aprender, de memorizar, de desenvolver uma cultura, ou de experimentar sensações.

Nesta perspectiva, a autonomia é pensada como uma característica biológica, mas também tecnológica, que determina a complexidade de um organismo ou de uma máquina. Fala-se então de graus de autonomia, que são diretamente relacionados aos níveis de inteligência e às formas de consciência da entidade em questão.

Para entender a autonomia em seus diversos níveis, recorremos aos estudos de Georges Chapouthier e Fédéric Kaplan (2011). Eles explicam a complexidade dos organismos vivos usando o termo étages emboîtés ${ }^{6}$ (CHAPOUTHIER; KAPLAN, 2011, p. 11). Segundo os pesquisadores, tendo como referência esta imagem, é possível decompor um organismo complexo em seus órgãos, que por sua vez são decompostos em células, e, assim por diante. A autonomia surge gradualmente em cada nível, correspondendo à complexidade do organismo:

Como em um mosaico no sentido artístico do termo, os seres vivos representam níveis intercalados, e, cada nível confere uma certa autonomia funcional aos níveis subjacentes. Como no mosaico, a imagem global confere a cada pedrinha, que a constituí sua cor, forma ou brilho ${ }^{7}$ (CHAPOUTHIER; KAPLAN, 2011, p. 15).

Chapouthier e Kaplan apontam ainda que, no caso dos objetos técnicos, a pesquisa sobre as possibilidades de projetar máquinas autônomas é uma tendência geral (CHAPOUTHIER; KAPLAN, 2011, p. 32-36). No centro dessa tendência encontra-se o esforço para construir uma memória, que possa reinterpretar experiências, aprender, mas também fazer previsões, projetando-se no futuro. Da mesma forma, os mecanismos de automação, autorregulação e controle são desenvolvidos para o mesmo objetivo, a fim de tornar as operações das máquinas mais autônomas.

KERINSKA, Nikoleta Tzvetanova. A autonomia em obras dotadas de inteligência artificial. PÓS:Revista do Programa de Pós-graduação em Artes da EBA/UFMG. v.10, n.19: mai.2020 Disponível em < $\underline{\text { https://eba.ufmg.br/revistapos }}>$ 
No contexto desta reflexão, a autonomia expressa a característica mais marcante dos trabalhos analisados. Assim, o conceito pode ser utilizado também para analisar o nível de interatividade e a evolução das obras dotadas com inteligência artificial. Entende-se que uma obra computacional pode ser considerada autônoma, na medida em que ela se comporta como uma entidade animada, capaz de reagir de forma independente, fornecendo ao público respostas imprevisíveis, que surgem nos processos de interação, ou implementando processos, cujo curso independe de comandos externos. Assim, a noção de autonomia é considerada como uma característica funcional das obras dotadas de inteligência artificial, que pode ser reconhecida tanto na simulação da criatividade, no uso da linguagem natural, ou ainda na evolução da obra, segundo regras próprias. É nesse sentido que se torna possível estabelecer uma analogia entre as obras de arte analisadas neste artigo e o conceito de autonomia, definido nos estudos sobre os seres vivos.

\section{Propensões artísticas}

Retomando os trabalhos analisados - PostPoète e Oscar, é possível detectar os traços autônomos específicos de cada trabalho. Oscar apresenta uma tentativa de simular a vida na forma de um ser consciente do seu ambiente. Sua capacidade de detectar a presença dos espectadores faz dele um personagem estranho e único. Uma câmera está posicionada logo acima do quadro que limita o espaço existencial de Oscar. Graças a ela, essa criatura virtual pode observar o ambiente externo, e detectar suas mudanças. Equipado com um programa de reconhecimento de imagem, ele se reposiciona para nos observar melhor. É no momento quando Oscar nos contempla com um olhar concentrado, que experimentamos, muitas vezes inconscientemente, seu comportamento autônomo. Essa presença ambígua e desconcertante releva do significado kantiano do conceito de autonomia, que dirige as escolhas do comportamento de Oscar: se aproximar lentamente, nos observar com atenção, ou, desaparecer bruscamente, rompendo esse instante mágico de cumplicidade, deixando o espectador sem reação (fig. 3).

KERINSKA, Nikoleta Tzvetanova. A autonomia em obras dotadas de inteligência artificial PÓS:Revista do Programa de Pós-graduação em Artes da EBA/UFMG. v.10, n.19: mai.2020 Disponível em < $\underline{\text { https://eba.ufmg.br/revistapos }>}$ 


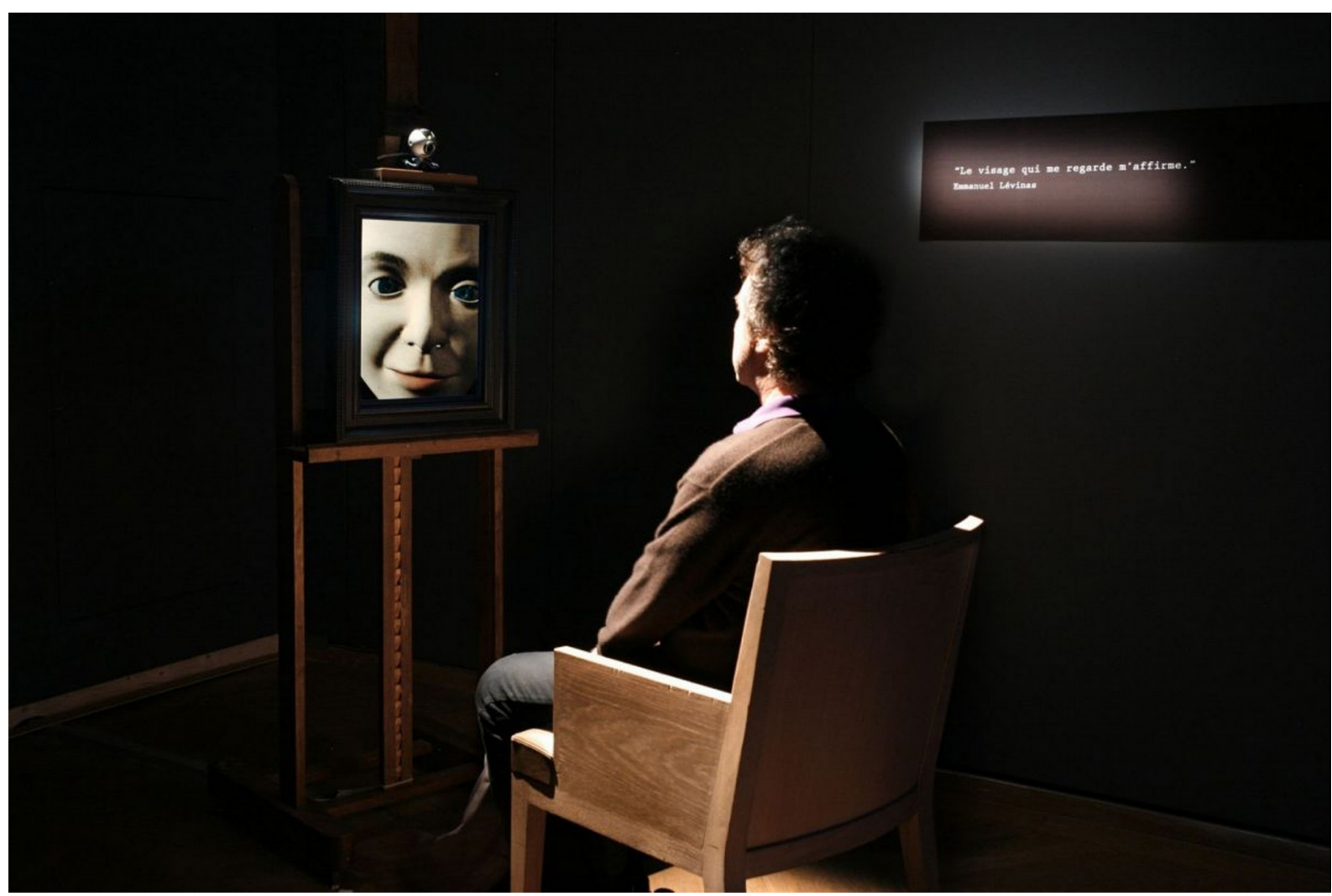

Fig. 3 - Vista da exposição do projeto Oscar no Festival VideoForms, 2015.

Fonte: Disponível em: <https://festival2015.videoformes.com/expos-2015/oscar/>. Acesso em: 12 de março 2020.

Para nós, é a presença de Oscar que nos desafia, que nos choca, enquanto, para seu criador, Louis Fléri, é a sua ausência que é ao mesmo tempo enigmática e poética. Ele escreve: "As ausências de Oscar me intrigam. O que ele faz durante esses minutos quando, devido ao jogo do algoritmo, ele se afasta do espectador, não o olha mais, afunda-se em si mesmo, até fechar os olhos como uma criança adormecida?" (IKAM; FLÉRI, 2007, p. 74). ${ }^{8}$ Nunca saberemos com certeza, mas qualquer resposta é plausível: Oscar se esconde para brincar conosco, ele se cansa de nos assistir, se dá um momento de intimidade dentro de seu programa, ele não quer que o considerem tão disponível! É esse jogo de presenças e ausências que transforma Oscar em um ser vivo - inconstante, incompressível, governado por suas percepções artificiais. Isto poderia ser um sinal da veracidade de sua existência? É uma prova de que ele realmente existe, e até mesmo afetivamente para o seu público?

KERINSKA, Nikoleta Tzvetanova. A autonomia em obras dotadas de inteligência artificial PÓS:Revista do Programa de Pós-graduação em Artes da EBA/UFMG. v.10, n.19: mai.2020 Disponível em < $\underline{\text { https://eba.ufmg.br/revistapos }>}$ 
O caso de PostPoète é, no entanto, bem diferente do de Oscar. Somos colocados em contato com as suas escritas, seu mundo poético e seu potencial literário. PostPoète é um escritor quieto, que compõe verso após verso. Como um poeta inspirado, PostPoète brinca com a linguagem, ele compõe imagens, ele conta. Qual é o seu propósito, além de nos questionar sobre nossas habilidades simbólicas, sobre a conquista maior e inegável dos humanos - nossa capacidade de criar e usar linguagens?

PostPoète é um trabalho que derrota a ideia de que a criatividade é um privilégio dos organismos vivos no sentido biológico do termo, que o uso da linguagem natural é estritamente humano, e que uma máquina nunca pode ser poética. Ao compartilhar suas rimas, essa escrita artificial, desencarnada e misteriosa nos leva a refletir sobre a força da linguagem, sobre as imagens mentais, que ela provoca e sobre a arte da interpretação. A autonomia criativa de PostPoète é inscrita em suas estruturas internas, cujas operações permanecem ocultas e opacas aos leitores humanos.

Esses são apenas dois exemplos de obras de arte, que usam meios computacionais, e que interagem de maneira que possamos reconhecer os traços essenciais do comportamento humano. Elas podem ser consideradas como parte de em um grupo de obras, que compartilha a ambição de explorar a fundo as conquistas científicas e o imaginário que se alimenta delas, para criar objetos interativos, que simulam a mente e o espírito humano. Entre seus objetivos primeiro são: aprender com a experiência, propor novas soluções para um problema, entender a linguagem natural, criar proposições visuais, musicais ou literárias autênticas, ou atuar no mundo, levando em consideração suas características físicas.

A maneira pela qual os artistas se apropriam das técnicas de inteligência artificial e os resultados artísticos produzidos por essa aliança entre arte e inteligência artificial determinam um novo território de pesquisa, cuja problemática é ainda recente, e conta com poucas abordagens dedicadas a suas especificidades. PostPoète e Oscar são dois projetos que permitem compreender e analisar a noção de autonomia dentro de uma obra em termos de interatividade e funcionamento. É nesse sentido que entendemos o conceito de autonomia, como um forte ponto de convergência entre certas realizações artísticas, e, as pesquisas que investigam a concepção de uma inteligência por meios artificiais.

KERINSKA, Nikoleta Tzvetanova. A autonomia em obras dotadas de inteligência artificial. PÓS:Revista do Programa de Pós-graduação em Artes da EBA/UFMG. v.10, n.19: mai.2020 Disponível em < $\underline{\text { https://eba.ufmg.br/revistapos }}>$ 


\section{REFERÊNCIAS}

CHAPOUTHIER, Georges; KAPLAN, Frédéric. L'homme, L’animal et la machine, Paris: CRNS, 2011.

DEKENS, Olivier. Fondements de la métaphysique de mœurs de Kant. Paris: Bréal, 2001.

FONSECA, João. Autopoiesis: Uma introdução as ideias de Maturana e Varela. Create Space Independent Publishing Platform, 25 mars 2008.

HEUDIN, Jean-Claude. Robots \& Avatars. Paris: Odile Jacob, 2009.

IKAM, Catherine; FLÉRI, Louis. Les absenses d'Oscar. In: Digital Diaries Paris: Maison Europeene de la Photographie, 2007.

KANT, Immanuel. Critique de la raison pratique, précédée de Fondements de la Métaphysique. Paris: Librarie Pylosophique de Ladrange, 1848.

MORIN, Jocelyne; BRIEF, Jean-Claude. L'autonomie humaine: une victoire sur l'organisme, Presses Universitaires de Québec, Québex, 1995.

KERINSKA, Nikoleta, Art et intelligence artificielle: dans le contexte d'une expérimentation artistique, tese de doutorado defendida na Universidade de Paris 1 Panthéon-Sorbonne, 2014.

MORIN, J.; BRIEF, J.-C. L'autonomie humaine - une conquiête de l'organisme. Québex: Presses Universitaires de Québec, 1995.

VARELA, Francisco; MATURANA, Humberto. Autopoiesis and Cognition: The Realization of the Living. Boston: Kluwer Academic Publishers, 1980.

KERINSKA, Nikoleta Tzvetanova. A autonomia em obras dotadas de inteligência artificial PÓS:Revista do Programa de Pós-graduação em Artes da EBA/UFMG. v.10, n.19: mai.2020

Disponível em < https://eba.ufmg.br/revistapos $>$ 


\section{NOTAS}

1 Citação original: “Tout d'abord, le mythe d'Ovide concentre à lui seul toutes les interrogations, tout les paradoxes et les fantasmes à propos des créatures artificielles, qu'il s'agisse de la tentation du démiurge, de créer un être à son image, de la quête de l'immortalité ou d'une altérité idéale,pour ne citer que ces quelques exemples". (Todas as traduções no texto são de responsabilidade da autora).

2 O poema "Quand mon fou théorique" foi composto por PostPoète. O programa é atualizado pela última vez em 12 de janeiro 2018. Disponível em: <http://postpoete.fr/>. Acesso em: 09 de janeiro 2018.

3 A origem etimológica da palavra autonomia é a seguinte: autos = si mesmo; nomos = lei, regra. Daí autonomia = capacidade ou direito de dar a si mesmo (a suas decisões ou ações) uma lei ou regra própria; o termo é traduzido para o inglês como self-gouvenement.

4 Sobre o assunto ver MORIN; BRIEF, 1995.

5 Nos referimos aqui ao livro de Chapouthier e Kaplan, intitulado L'homme, l'animal et la machine (p. 5-7).

6 Tradução do termo étages eboîtés: étages = andares, no sentido de níveis, e emboîtés = encaixados, no sentido de intercalados.

7 Citação original: "Comme dans une mosaïque au sens artistique du terme, les êtres vivants sont des emboîtements d'étages, où chaque étage laisse une autonomie de fonctionnement aux étages sous-jacents. Comme dans la mosaïque, l'image d'ensemble laissait aux tesselles qui la constituent leur couleur, leur forme ou leur brillance".

8 Citação original: “Les absence d'Oscar m'intriguent. Que fait-il pendant ces minutes où, par le jeu d'un algorithme, il se détache de vous, ne vous regarde plus, s'enfonce en lui même, jusqu'à fermer les yeux comme un enfant endormi ?" 